is $24 \frac{1}{2}$ pounds, its greatest length is 27 inches, its thickness (in direction of the ortho axis), is 4 inches, and its breadth (at right angles to the ortho axis) is six inches.

The angles of the crystal were taken with the hand goniometer. The most noticeable fact is that the unit prism of $111^{\circ} 30^{\prime}$ occurs only on a curious prismatic extension, composed of this prism and a clino prism (470), which pierces the pyramidal plane 111 and extends upward about one inch to the basal plane common to this and the rest of the crystal as show $n$ in the figure. The prism which occurs on the rest of the crystal has an angle of

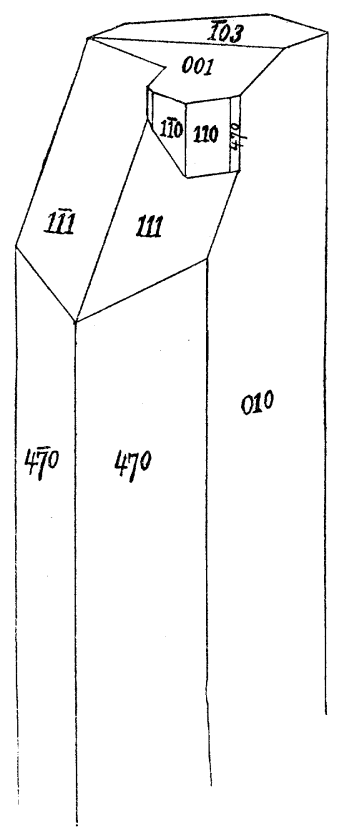

approximately $79^{\circ}$, corresponding to the clino prism $i-\frac{i}{4}(470)$, and all its faces are striated rertically while those of the unit prism are smooth.

The other occurring forms are $\iota-\grave{i}(010),-1(111), \frac{1}{3}-i(\overline{1} 03)$, and $O$ (001). The cleavages parallel to (010), $(\overline{101})$ and $(\overline{1} 11)$ were visible in the break at the lower end.

At least six phantom terminations can be seen apparently parallel to (001) and (103).

\section{DISTANCE AND COLOR PERCEPTION BY INFANTS.}

$$
\text { BY J. MARK BALDWIN, PRINCETON, N. J. }
$$

I UNDERTOOK at the beginning of my child H's 9 th month to experiment with her with a view to arriving at the exact state of her color perception, employing the new method which I described and compared with other methods in a recent paper in this journal. ${ }^{1}$ The method consisted in this instance in giving the infant a comfortable sitting posture, kept constant by a band passing around her chest and fastened securely to the back of her chair. Her arms were left bare and quite free in their movements. Pieces of paper of different colors were exposed before her, at varying distances, front, right, and left. This was regulated by a frame-work, consisting of a horizontal graded (in inches) rod, projecting from the back of the chair at a level with her shoulder and parallel with her arm when extended straight forward, and carrying on it another rod, also graded in inches, at right-angles to the first. This second rod was thus a horizontal line directly in front of the child, parallel with a line connecting her two shoulders, and so equally distant for both hands. This second rod was made to slide upon the first, so as to be adjusted at any desirable distance from the child. On this second rod the colors, etc., were placed in succession, the object being to excite the child to reach for the color.

So far from being distasteful to the infant, I found that with pleasant suggestions thrown about the experiments, the whole

$$
1 \text { Science, April 21, } 1893 .
$$

procedure gave her the most intense gratification, and the affair became her most pleasant daily occupation. After each sitting she was given a reward of some kind.

The accompanying tables give the results, both for color and distance, of 217 experiments. Of these 111 were with five colors and 106 with ordinary newspaper (chosen as a relatively neutral object, which would have no color value and no association to the infant). In the tables $R$ stands for "refusal" (to reach out for the object), $A$ for "acceptance" (and effort), $N$ for the entire number of experiments with each color respectively, and $n$ for the entire number with all the colors at each distance respectively. So $\frac{A}{N}=$ the proportion of responses or efforts for any color, and $\frac{R}{n}=$ the proportion of refusals for each distance.

\begin{tabular}{|c|c|c|c|c|c|c|c|c|c|}
\hline $\begin{array}{l}\text { Distance, } \\
\text { inches. }\end{array}$ & 9 & 10 & 11 & 12 & 13 & 14 & 15 & Totals. & Ratio $\frac{A}{\bar{N}}$ \\
\hline & R. A. & R. A. & R. A. & R. A. & R. A. & R. A. & R. A. & R. A. N. & \\
\hline Blue. & $0-1$ & $0-4$ & $0-5$ & $1-3$ & $2-4$ & $1-5$ & $3-1$ & $7-23-30$ & $.762 / 3$ \\
\hline Red. & $0-1$ & $0-3$ & $2-2$ & $1-4$ & $1-7$ & $1-7$ & $5-1$ & $10-25-35$ & $.711 / 2$ \\
\hline White. & $0-0$ & $0-0$ & $0-0$ & $0-1$ & $0-5$ & $1-1$ & $3-0$ & $4-7-11$ & $.632 / 3$ \\
\hline Green. & $0-0$ & $0-1$ & $0-1$ & $2-i$ & $1-4$ & $1-2$ & $2-0$ & $7-9-16$ & $.561 / 3$ \\
\hline Brown. & $0-1$ & $0-2$ & $2-1$ & $3-2$ & $0-3$ & $3-1$ & $2-0$ & $11-10-21$ & $.471 / 2$ \\
\hline Totals. & $0-3$ & $0-10$ & $4-9$ & $7-11$ & $4-23$ & $7-16$ & $15-2$ & $37-74-111$ & .67 \\
\hline Ratio $\frac{R}{n}$ & 0 & 0 & $.331 / 3$ & .39 & .15 & $.301 / 2$ & .89 & & \\
\hline
\end{tabular}

Table $I$.

Table II.

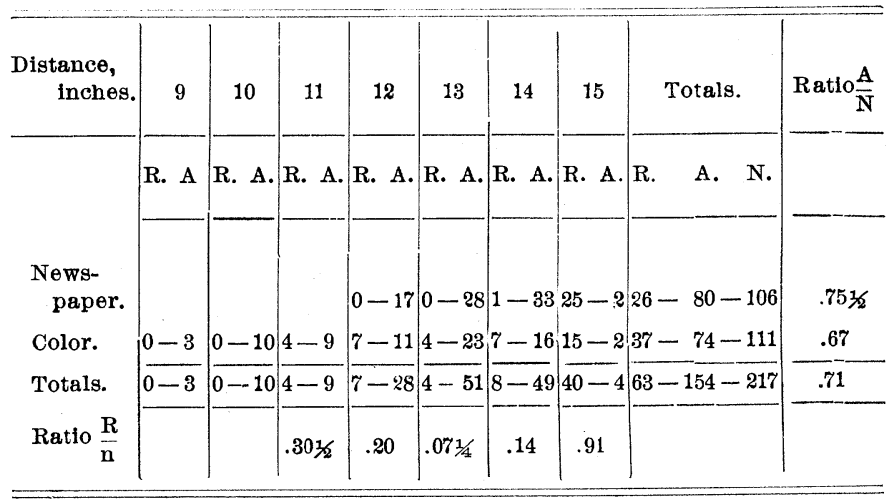

Color. - The results are evident in the tables (I. and II.), especially the columns marked "Ratio $\frac{A}{N}$ " and "Ratio $\frac{R}{n}$." The colors range themselves in the order of attractiveness, i.e., blue, red, white, green, and brown. The difference between blue and red is very slight compared to that between any other two. This confirms Binet as against Preyer (who puts blue last), and also fails to confirm Preyer in putting brown before red and green. Brown to my child - as tested in this way - seemed to be about as neutral as could well be. White, on the other hand, was more attractive than green. I am sorry that my list does not include yellow. The newspaper was, at reaching distance (9 to 10 inches) and a little more (up to 14 inches), as attractive as the average of the colors, and even as much so as the red; but this is probably due to the fact that the newspaper experiments came after a good deal of practice in reaching after colors, and a more exact association between the stimulus and its distance. At 15 inches and over, accordingly, the newspaper was refused in more than 92 per cent of the cases, while blue was refused at that distance in only 75 per cent, and red in 84 per cent.

Distance. - In regard to the question of distance, the child persistently refused to reach for anything put 16 inches or more away from her. At 15 inches she refused 91 per cent of all the 
cases, 89 per cent of the color cases, and, as I have said, 92 per cent of the newspaper cases. At nearer distances we find the remarkable uniformity with which the safe-distance association works. At 14 inches only 14 per cent of all the cases were refused, and at 13 inches only about 8 per cent. The fact that there was a larger percentage of refusals at 11 and 12 inches than at 13 and 14 inches is seen from the table (I.) to be due to the influence of the brown, which was refused consistently when more than 10 inches away. The fact that there were no refusals to reach for anything exposed within reaching distance (10 inches) - other attractive objects being kept away - shows two things: (1) the very fine estimation visually of the distance represented by the arm-length, thus emphasizing the element of muscular sensation in the perception of distance generally; and (2) the great uniformity at this age of the phenomenon of "sensorimotor suggestion" 1 upon which this method of child study is based.

In regard to the relative use of the two hands in these and other experiments, - this is a topic to which I wish to devote another paper, giving details upon which certain conclusions (announced in an earlier note in this journal) are based. ${ }^{2}$

\section{LETTERS TO THE EDITOR.}

$*_{*}^{*}$ Correspondents are requested to be as brief as possible. The vriter's name is in all cases required as proof of good faith.

On request in advance, one hundred copies of the number containing his communication will be furnished free to any correspondent.

The editor will be glad to publish any queries consonant with the character of the journal.

The Convex Profile of Bad-Land Divides.

UNDER this caption Professor W. M. Davis, in Science, Oct. 28, 1892, discusses the "missing factor" in Gilbert's "Law of Divides," and concludes that it is "the creeping of the surface soil."

In my class-room lectures, and in a paper forwarded four months ago to the secretary of the Geological Society of America, but not yet published, I also have attempted an explanation of this missing factor. I mention this merely for the truth of his. tory, not that I care much for the credit of priority, or fear the charge of plagiarism when my explanation appears. Its independent origin will be self-evident, because I have approached the problem in a very different way.

Both Professor Davis and Mr. Gilbert seem inclined to regard bad-land forms as something apart from land-sculpture in general - something which requires special explanation - while I have cited general laws and deduced these forms from them. My paper is entitled "Some Elements of Land-Sculpture: Water Curves, Weather Curves, and Structural Angles." Water curves are either horizontal, e.g., the serpentine course of a river, or vertical. The vertical water curve of erosion is concave upwards, e.g., the normal gradient of a stream excavating its channel in homogeneous material (b.c. Fig. 3); and the vertical water curve of deposition is convex upward, e.g., a dêbris fan, or alluvial cone.

All weather curves are convex upward. This fundamental law of the weather curve I have deduced theoretically in two ways, and that it is confirmed by observation almost goes without saying. An angular structural block, $A$, Fig. 1, is rounded by

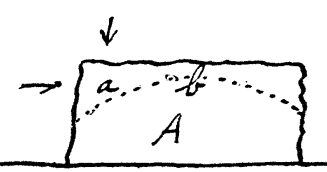

Fig. 1. - A structural block rounded by weathering. The dotted line is the weather curve, convex upward.

weathering, that is, its outline becomes a flowing curre, convex upward, like the dotted line in the figure, because the protruding angles are more exposed to attack, and at the same time the products of disintegration are in a position to be quickly removed.

'See my article on "Suggestion in Infancy," Science, xvi1., 1891, p. 113; als my "Handbook of Psychology," Vol. II., pp. $297 \mathrm{ff}$.

2 Science, xvi., 1890, p. 24 r
The complex forces included under the general term weathering have a double advantage at $a$ as compared with $b$, because the attack comes from two directions. Moreover, the removal of loosened particles, whether by falling raindrops, by winds, or by gravitation (one effect of which is creeping), proceeds many times faster at $a$ than at $b$. By a similar but slightly modified process of reasoning, it may be shown that a sharp crest triangular in cross-section would be rounded also by weathering (c.f. La Noé and Margarie, Les Formes du Terraines).

Another method of deducing the upward convexity of weather curves is that which is based upon the law of slopes in relation to hardness. The harder the rock the steeper the slope, other things being equal. Let 1,2,3, and 4 (Fig. 2) denote strata which grade regularly downward in hardness, No. 1 being hardest of all. Then if the products of disintegration are at once and completely

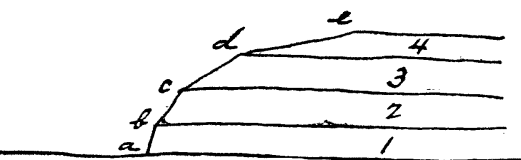

Fig. 2. - Convex slope formed by the weathering of rocks which regularly increase in hardness downwards.

removed, as, for instance, by a stream flowing at $a$, the hard rock, No. 1, will form a cliff $a b$, while $b c$ will be less steep, $c d$ still less steep, and de very gentle. Each element; of the slope, e.g., $b c$, is a straight line in cross-section, but thelgeneral effect is that of a curve; and if the beds were very thin it would pass from a broken line to a true flowing curve, convex upward. Now we may conceive the series $1,2,3,4$ to have been originally homogeneous, and that weathering has softened the upper members. In that case the downward gradation in bardness would be by in. finitessimal laminæ, and the resultant slope a typical weather curve.

Ordinarily, the convexity does not extend to the bottom, because the weather curve is there replaced by the vertical water curve of erosion. This combination of weather and water curves modifying structural blocks yields the form shown in Fig. 3, the

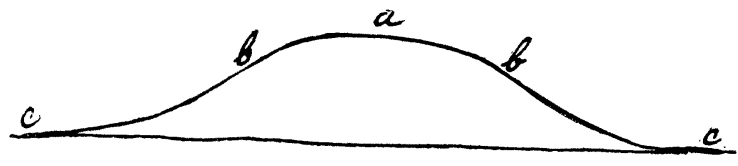

Fia. 3. - Cross-section of any ordinary ridge or hill

most typical, as it is also the most familiar and universal of earthforms. The upper part, $a b$, of each slope is a weather curve, convex upward, and the lower part, $b c$, is a water ourve, concave upward. Bad-land divides are excellent examples of the general law, instead of being exceptions to it. The convex profile of the summit which puzzled Gilbert is simply the familiar and omnipresent weather curve. The only thing exceptional about it in the bad-lands is its narrowness and sharpness of curvature. That depends chietly upon the early stage of the base-levelling in those regions, as I have shown in my forthcoming paper.

Creeping is a real factor in the rounding of divides, but is only one phase of the secondary process of transportation. Disintegration is the primary process. And in the subsequent movement of loosened particles, falling raindrops, gusts of rain driven aslant by winds, the winds themselves, the rolling and tumbling effects of gravitation as distinguished from the slow process of creeping - all these are active and efficient agents of removal. Their combined effects overshadow the results of creeping, especially on the bare, sharp ridges of the bad-lands. The clays are compact and firmly adherent. It is on gentle and turf-bound slopes that the slow process of creeping is relatively most effective.

Nor do I agree that the weather curve on the summit of badland ridges would be obliterated if the rainfall should increase. The effect of falling raindrops belongs to the category of weathering, and produces convex curves. It is only when the fallen drops gather iuto rills and begin to flow that the concave water curve of erosion begins to form. Hence increased rainfall would 